\title{
Kepatuhan Kunjungan Antenatal Care terhadap Sikap dalam Deteksi Dini Komplikasi Kehamilan pada Ibu Hamil
}

\author{
Hardaniyati $^{1 *}$, Dian Soekmawaty R.A.1), Yadul Ulya ${ }^{1)}$ \\ Email: hardaniyatidaniya88@gmail.com \\ 1) STIKES YARSI MATARAM
}

\begin{abstract}
ABSTRAK
Pelayanan antenatal adalah prosedur yang secara rutin dilakukan oleh petugas kesehatan dalam membina hubungan yang baik didalam proses pelayanan pada ibu hamil untuk deteksi dini, pengawasan selama kehamilan dan persiapan persalinan. Salah satu faktor yang kurang dimanfaatkan dalam pelayanan antenatal care antara lain rendahnya pengetahuan dan pemahaman ibu hamil. Kepatuhan dalam kunjungan ANC bertujuan untuk memantau keadaan ibu dan janin, untuk mendeteksi masalah secara dini dan memberikan tindakan atau intervensi yang tepat, dan mengetahui jika ada komplikasi pada kehamilan. Penelitian ini bertujuan untuk mengetahui kepatuhan kunjungan antenatal care terhadap sikap dalam deteksi dini komplikasi pada ibu hamil. Metode yang digunakan yaitu studi pencarian sistematis data base terkomputerisasi (research gate, pubmed, google cendekia) digunakan untuk mencari hasil publikasi dengan pembatasan pada desain penelitian cross sectional. Berdasarkan 6 artikel yang dianalisis menunjukan bahwa ada hubungan kepatuhan kunjungan antenatal care terhadap sikap dalam deteksi dini kehamilan pada ibu hamil. Semakin tinggi tingkat kepatuhan kunjungan antenatal care maka semakin baik perilaku ibu hamil dalam mendeteksi dini komplikasi Ibu hamil yang patuh melakukan kunjungan Antenatal care mempunyai sikap yang positif terhadap deteksi dini komplikasi kehamilan maka ibu akan lebih peka terhadap cara atau berperilaku dalam mencegah,karena infeksi menular.
\end{abstract}

Kata kunci: Kepatuhan, Antenatal Care, Sikap

\begin{abstract}
Antenatal care is a procedure that is routinely carried out by health workers in fostering good relationships in the service process to pregnant women for early detection, supervision during pregnancy and preparation for childbirth. One of the underutilized factors in antenatal care services is the lack of knowledge and understanding of pregnant women. Compliance in the ANC visit aims to monitor the condition of the mother and fetus, to detect problems early and provide appropriate action or intervention, and find out if there are complications in pregnancy. This study aims to determine the adherence of antenatal care visits to attitudes in early detection of complications in pregnant women. Methods a systematic search study of computerized databases (research gate, pubmed, google scholar) was used to search for publications with limitations on cross-sectional research design. Based on the 6 articles analyzed, it shows that there is a relationship between adherence to antenatal care visits and attitudes in early detection of pregnancy in pregnant women. Conclusion The higher the level of adherence to antenatal care visits, the better the behavior of pregnant women in early detection of pregnancy complications, so the mother will know what the risks of pregnancy and pregnancy complications are, thus making pregnant women aware and motivated to comply in conducting ANC check-ups.
\end{abstract}

Keywords: Compliance, Antenatal Care, Attitude

\section{A. LATAR BELAKANG}

Komplikasi kehamilan adalah masalah kesehatan yang sering terjadi selama kehamilan dan berdampak pada kesehatan ibu, kesehatan bayi saat dilahirkan. Masalah kesehatan ibu dapat terjadi sebelum kehamilan dan pada akhirnya akan berdampak komplikasi pada masa kehamilan, pada masa kehamilaan memerlukan perhatian khusus untuk menentukan kualitas hidup selanjutnya, untuk menghadapi ancaman tersebut salah satu persiapan yang dilakukan yaitu dengan aktif melakukan kunjungan 
Antenatal Care sehingga bisa dilakukan deteksi [1].

Dengan deteksi dini selama kehamilan sejak awal kunjungan dapat menurunkan angka kematian ibu dan memantau keadaan kesejahtraan janin. Melalui deteksi dini kelainan yang timbul selama masa kehamilan akan cepat diketahui dan segera dapat diatasi sebelum berpengaruh buruk terhadap ibu. Angka kematian yang sangat tinggi dapat menggambarkan tingginya wanita hamil yang mengalami komplikasi kehamilan yang tidak terdeteksi lebih dini yang menyebabkan ibu hamil tidak mendapatkan penangganan awal, hal tersebut terjadi dikarenakan ibu tidak melakukan kunjungan Antenatal care terkhusus pada K1. Ibu hamil yang patuh melakukan kunjungan Antenatal care mempunyai sikap yang positif terhadap deteksi dini komplikasi kehamilan maka ibu akan lebih peka terhadap cara atau berperilaku dalam mencegah,karena infeksi menular, 30\% kematian karena diare, dan 18\% kematian karena gangguan pernapasan akut [2].

Antenatal Care merupakan suatu pelayanan kesehatan kehamilan yang diterima ibu pada masa kehamilan. Kunjungan ANC salah satu hal yang penting untuk mengurangi angka kematian ibu dan anak [3]. Menurut WHO merekomendasikan untuk kunjungan antenatal care minimal delapan kali. Kunjungan pertama pada trimester I umur kehamilan 0-12 minggu, kunjungan trimester II umur kehamilan 20 dan 26 minggu, dan untuk kunjungan trimester III umur kehamilan 30, 34, 36, 38, 40 minggu. Untuk mengetahui capaian kunjungan kesehatan yang pernah dilakukan oleh ibu hamil dapat dinilai dengan menggunakan indikator cakupan K1 dan K4. K1 yaitu jumlah ibu hamil yang telah melakukan kunjungan pelayanan Antenatal Care pertama sedangkan $\mathrm{K} 4$ yaitu jumlah ibu hamil yang telah melakukan pelyanan Antenatal care sesuai dengan standar yang sudah di tentukan standar paling sedikit empat kali.

World Health Organization (WHO) [4], mengemukakan angka kematian ibu di dunia sebesar 810 kematian per 100.000 kelahiran hidup per hari, dan data kematian ibu di $A S E A N$ menunjukkan Indonesia menempati urutan kedua tertinggi. Profil Kesehatan Indonesia menunjukkan hasil data dari Survei Demografi Kesehatan Indonesia (SDKI) melaporkan Angka Kematian Ibu (AKI) secara umum terjadi penurunan selama periode 1991-2015 dari 390 menjadi 305 per 100.000 kelahiran hidup. Walaupun terjadi suatu penurunan angka kematian ibu, namun tidak berhasil mencapai target $M D G s$ yang harus dicapai yaitu sebesar 102 per 100.000 kelahiran hidup pada tahun 2015. [5]

Program safe motherhood dilakukan dengan mempromosikan kesehatan ibu yang berfokus pada pengetahuan dan perilaku dengan memberikan Pendidikan kesehatan pada masyarakat yang dapat meningkatkan penggunaan pelayanan antenatal care sehingga rendahnya cakupan $\mathrm{K} 4$ dapat teratasi dan tercapainya pelayanan ANC sesuai standar yang ditentukan [6].

Berdasarkan latar belakang di atas penyusun tertarik untuk membuat iterature review dengan judul "Kepatuhan Kunjungan Antenatal Care Terhadap Sikap Dalam Deteksi Dini Komplikasi Kehamilan Pada Ibu Hamil.

\section{B. METODE PENELITIAN}

Studi ini merupakan suatu tinjauan literatur (literature review) yang mencoba menggali tentang "kepatuhan kunjungan antenatal care terhadap sikap dalam deteksi dini komplikasi kehamilan pada ibu hamil. Sumber untuk melakukan tinjuan literatur ini meliputi studi pencarian sistematis data base terkomputerisasi, researchgate, pubmed, google cendekia) dalam bentuk jurnal penelitian berjumlah 6 , penulisan artikel ini menggunakan penulisan daftar pustaka Harvard. 


\section{HASIL DAN PEMBAHASAN}

Tabel 1. Hasil Penelitian dari Tinjauan Literatur

\begin{tabular}{|c|c|c|c|c|}
\hline Tahun & Penulis & Judul & Metode & Hasil \\
\hline 2020 & $\begin{array}{l}\text { Sri Untari, } \\
\text { Sehmawati }\end{array}$ & $\begin{array}{l}\text { Hubungan Tingkat } \\
\text { Kepatuhan Ibu } \\
\text { Hamil Dalam } \\
\text { Antenatal Care } \\
\text { (Anc) Dengan } \\
\text { Deteksi Dini } \\
\text { Komplikasi } \\
\text { Kehamilan }\end{array}$ & $\begin{array}{l}\text { Penelitian ini Survei } \\
\text { Analitik dengan } \\
\text { menggunakan } \\
\text { desain Cross } \\
\text { Sectional }\end{array}$ & $\begin{array}{l}\text { Hasil penelitian uji } \\
\text { statistik menunjukkan } \\
\text { bahwa tingkat } \\
\text { kepatuhan ibu dalam } \\
\text { Antenatal Care (ANC) } \\
\text { mempunyai hubungan } \\
\text { yang bermakna } \\
\text { dengan deteksi dini } \\
\text { komplikasi kehamilan } \\
\text { dengan masing- } \\
\text { masing nilai X2 } \\
\text { hitung 7,26 yang lebih } \\
\text { besar dari X2 tabel } \\
\text { 3,84. }\end{array}$ \\
\hline 2009 & Erni Damayanti & $\begin{array}{l}\text { Hubungan Tingkat } \\
\text { Pengetahua n Ibu } \\
\text { Hamil Tentang } \\
\text { Resiko Tinggi } \\
\text { Kehamilan Dengan } \\
\text { Kepatuhan } \\
\text { Kunjungan } \\
\text { Antenatal Care. }\end{array}$ & $\begin{array}{l}\text { Penelitian ini Survei } \\
\text { Analitik dengan } \\
\text { menggunakan } \\
\text { desain Cross } \\
\text { Sectional }\end{array}$ & $\begin{array}{l}\text { Hasil penelitian } \\
\text { menunjukan, ada } \\
\text { hubungan antara } \\
\text { pengetahuan dengan } \\
\text { kepatuhan kunjungan } \\
\text { antenatal care tentang } \\
\text { resiko tinggi dalam } \\
\text { deteksi dini } \\
\text { komplikasi kehamilan. }\end{array}$ \\
\hline 2018 & $\begin{array}{l}\text { Reni yuli astutik, } \\
\text { Tia rusdianawati }\end{array}$ & $\begin{array}{l}\text { Kepatuhan } \\
\text { Antenatal Care Ibu } \\
\text { Hamil Resiko } \\
\text { Tinggi Dengan } \\
\text { Ketepatan Rujukan }\end{array}$ & $\begin{array}{l}\text { Penelitian ini survei } \\
\text { Analitik desain } \\
\text { korelasi dengan } \\
\text { pendekatan Cross } \\
\text { Sectional. }\end{array}$ & $\begin{array}{l}\text { Hasil penelitian } \\
\text { menujukan ada } \\
\text { hubungan antara } \\
\text { kepatuhan antenatal } \\
\text { care ibu hamil resiko } \\
\text { tinggi dengan } \\
\text { ketepatan rujukan. } \\
\text { Nilai p<0.001 }\end{array}$ \\
\hline 2020 & $\begin{array}{l}\text { Retno Palupi, } \\
\text { Yonni Siwi }\end{array}$ & $\begin{array}{l}\text { Analisis } \\
\text { Kepatuhan } \\
\text { Kunjungan } \\
\text { Antenatal Care } \\
\text { Terhadap Sikap } \\
\text { Dalam Deteksi } \\
\text { Dini Komplikasi } \\
\text { Kehamilan Pada } \\
\text { Ibu Hamil }\end{array}$ & $\begin{array}{l}\text { Penelitian ini } \\
\text { Observasional } \\
\text { dengan pendekatan } \\
\text { cross sectional. }\end{array}$ & $\begin{array}{l}\text { Hasil penelitian nilai } \mathrm{p} \\
=0,000 \text { dan } \mathrm{R} 0,855, \\
\text { ada pengaruh } \\
\text { Kepatuhan Kunjungan } \\
\text { Antenatal Care } \\
\text { Terhadap Sikap } \\
\text { Dalam Deteksi Dini } \\
\text { Komplikasi } \\
\text { Kehamilan Pada Ibu } \\
\text { Hamil, sebesar } 85,8 \% \text {. } \\
\text { Semakin ibu hamil }\end{array}$ \\
\hline
\end{tabular}




\begin{tabular}{|c|c|c|c|c|}
\hline Tahun & Penulis & Judul & Metode & Hasil \\
\hline & & & & $\begin{array}{l}\text { patuh melakukan } \\
\text { kunjungan Antenatal } \\
\text { Care maka ibu akan } \\
\text { memiliki sikappositif } \\
\text { dalam deteksi dini } \\
\text { komplikasi kehamilan. }\end{array}$ \\
\hline 2016 & $\begin{array}{l}\text { Meyliya Qudriani, } \\
\text { Seventina,Nurul } \\
\text { Hidayah }\end{array}$ & $\begin{array}{l}\text { Persepsi Ibu Hamil } \\
\text { Tentang } \\
\text { Kehamilan Resiko } \\
\text { Tinggi Dengan } \\
\text { Kepatuhan } \\
\text { Melakukan } \\
\text { Antenatal Care }\end{array}$ & $\begin{array}{l}\text { Metode Analitik } \\
\text { dengan } \\
\text { menggunakan } \\
\text { desain Cross } \\
\text { Sectional }\end{array}$ & $\begin{array}{l}\text { Hasil uji korelasi pada } \\
\text { penelitian menunjukan } \\
\text { p value } 0,030<0,05 \\
\text { terdapat hubungan } \\
\text { yang bermakna antara } \\
\text { persepsi ibu hamil } \\
\text { tentang kehamilan } \\
\text { resiko tinggi dengan } \\
\text { kepatuhan antenatal } \\
\text { care. }\end{array}$ \\
\hline 2012 & $\begin{array}{l}\text { Ratna Sari } \\
\text { Hardiani, } \\
\text { Agustin Purwanti }\end{array}$ & $\begin{array}{l}\text { Motivasi Dan } \\
\text { Kepatuhan } \\
\text { Kunjungan } \\
\text { Antenatal Care } \\
\text { (Anc) Pada Ibu } \\
\text { Hamil Trimester } \\
\text { III }\end{array}$ & $\begin{array}{l}\text { Metode Analitik } \\
\text { dengan } \\
\text { menggunakan } \\
\text { desain Cross } \\
\text { Sectional }\end{array}$ & $\begin{array}{l}\text { Hasil penelitian } \\
\text { menujukan sebagian } \\
\text { besar responden } \\
\text { menujukan motivasi } \\
\text { yang baik dan } \\
\text { kepatuhan terhadap } \\
\text { kunjungan antenatal } \\
\text { care pada ibu hamil } \\
\text { trimester III. Dengan } \\
\text { nilai (OR; } 5.935 \mathrm{p} \text { : } \\
0.002 .)\end{array}$ \\
\hline
\end{tabular}

Berdasarkan hasil penelitian pada tabel 1 dapat diketahui bahwa ada hubungan antara kepatuhan kunjungan antenatal care terhadap sikap dalam deteksi dini komplikasi kehamilan pada ibu hamil. Kepatuhan diartikan sebagai bentuk yang timbul akibat adanya interaksi antara petugas kesehatan dan pasien sehingga pasien mengerti rencana dengan segala konsekuensinya dan menyetujui rencana tersebut. Ibu hamil yang patuh melakukan kunjungan Antenatal care mempunyai sikap yang positif terhadap deteksi dini komplikasi kehamilan maka ibu akan lebih peka terhadap cara atau berperilaku dalam mencegah, karena infeksi menular [7].

Hasil penelitian Yuli [8] menyebutkan bahwa ibu hamil yang memeriksakan kehamilannya tidak sesuai dengan Standar Asuhan Antenatal Care (ANC) yang telah ditetapkan juga sebagai resiko mengalami komplikasi kebidanan. Hal tersebut terjadi karena kehamilan ibu, perkembangan janin dan kegawatdaruratan yang mungkin terjadi saat persalinan tidak dapat dicegah dan diminimalisir sedini mungkin. Pemeriksaan antenatal care lebih dari 4 kali berhubungan dengan peningkatan kehamilan resiko tinggi dan persalinann Tindakan, kurangnya pemeriksaan antenatal care berkaitan dengan rendahnya scor apgar sehingga pemeriksaan antenatal care yang adekuat merupakan faktor yang penting dalam menurunkan angka kematian ibu dan bayi.

Dalam penelitian Armaya [9] menyatakan tingkat pengetahuan merupakan suatu langkah 
perantara dalam proses pengambilan keputusan oleh seseorang, yang akhirnya akan membawa perubahan pada tingkah laku. Penjelasan Kurniasih [8] juga menyatakan bahwa tingkat pengetahuan ibu tentang deteksi dini komplikasi kehamilan sangat penting, karena jika seseorang didasari dengan pengetahuan yang baik akan hal tersebut maka ibu akan tau apa saja resiko yang akan terjadi selama kehamilan dan akan membuat ibu lebih peduli dan termotivasi untuk patuh melakukan kunjungan ANC, berguna untuk mencegah resiko dan komplikasi kehamilan agar ibu dan janin tetap sehat, serta dapat meningkatkan kualitas hidup ibu dan bayi. Temuan ini sejalan dengan temuan Noviati [10] yang menyatakan bahwa semakin tinggi tingkat pengetahuan ibu maka akan semakin patuh ibu hamil dalam melakukan pemeriksaan ANC. Kurangnya pengetahuan ibu deteksi dini komplikasi kehamilan menyebabkan kurangnya mendapatkan informasi mengenai kesehatan ibu dan janin, serta resiko yang akan terjadi apabila tidak rutin melakukan kunjungan ANC.

Menurut Wawan [11] faktor - faktor yang mempengaruhi kunjungan kepatuhan ANC adalah faktor kebutuhan. Pemeriksaan kehamilan secara teratur akan dilakukan oleh ibu hamil, bila tindakan itu dirasakan sebagai kebutuhan. Faktor kebutuhan ini merupakan dasar stimulus paling langsung untuk menggunakan sarana kesehatan dalam menjaga kesehatannya selama kehamilan. Faktor selanjutnya adalah harapan, ibu melakukan pemeriksaan kehamilan ke tenaga kesehatan dengan harapan agar kesehatannya selama kehamilan terjamin dan terdeteksi sedini mungkin serta apabila ada komplikasi yang terjadi dapatsegera diatasi/ditangani [6].

Menurut penelitian Purnami [12] menyatakan Kepatuhan kunjungan Antenatal Care (ANC) dapat diartikan sebagai ketaatan dalam berkunjung ke tempat pelayanan kesehatan oleh ibu hamil sesuai dengan saran petugas kesehatan yaitu bidan atau dokter spesialis sesuai dengan standar Antenatal Care
(ANC) yang ditetapkan. Ketidakpatuhan ANC menyebabkan tidak dapat diketahuinya berbagai komplikasi yang mempengaruhi kehamilan atau komplikasi hamil sehingga tidak dapat terdeteksi secara maksimal sehingga sangat berpengaruh terhadap ketepatan rujukan. Penelitian ini sejalan dengan penelitian Jasmawati [13] Usia reproduktif pada ibu hamil dapat mempengaruhi kepatuhan ibu hamil dalam melakukan kunjungan ANC dikarenakan ibu hamil dengan usia muda mempunyai daya ingat yang lebih kuat dan kreativitas tinggi dalam mencari dan mengenal sesuatu yang belum diketahui selain juga mudah menyerap pengetahuan / informasi sehingga lebih memiliki kesadaran untuk melakukan kunjungan ANC serta mempersiapkan upaya persalinan.

Berdasarkan hasil penelitian Oktavia [14] juga mengatakan bahwa pengalaman seorang ibu hamil tentang keberhasilan atau ketidakberhasilannya tentang pengobatan terhadap suatu penyakit berpengaruh dan dapat meningkatkan pengetahuan karena informasi yang mereka dapatkan dari tenaga medis. Setiap kehamilan memiliki potensi dan membawa resiko bagi ibu dan janin sampai menimbulkan kematian ibu dan bayi, maka dari itu sangat penting ibu hamil patuh dalam melakukan pemeriksaan ANC minimal 4x untuk mendeteksi dini dan komplikasi kehamilan dapat dicegah, agar ibu dapat mengetahui kesehatan ibu dan janin. Karena dengan ibu patuh melakukan pemeriksaan kehamilan, itu merupakan sebuah kunci keberhasilan dalam penurunan angka kematian ibu dan bayi.

Pengetahuan tentang manfaat sesuatu program (manfaat pelayanan ANC) menyebabkan seorang ibu hamil mempunyai sikap yang positif dan akan mempengaruhi ibu untuk melakukan kunjungan antenatal. Semakin tinggi tingkat pengetahuan seseorang, maka perilaku akan lebih bersifat langgeng ibu yang tahu dan paham tentang jumlah anak yang ideal, maka ibu akan berperilaku sesuai dengan apa yang ia ketahui [15]. 


\section{KESIMPULAN}

Berdasarkan hasil penelitian dapat ditarik kesimpulan Semakin tinggi tingkat kepatuhan kunjungan antenatal care maka semakin baik perilaku ibu hamil dalam mendeteksi dini komplikasi kehamilan maka ibu akan tahu apa saja resiko kehamilan dan komplikasi kehamilan, Ibu hamil yang patuh melakukan kunjungan Antenatal care mempunyai sikap yang positif terhadap deteksi dini komplikasi kehamilan maka ibu akan lebih peka terhadap cara atau berperilaku dalam mencegah, karena infeksi menular.

\section{E. UCAPAN TERIMA KASIH}

Terima kasih kami ucapkan kepada para editor dan reviewer yang telah berkontribusi dengan meluangkan waktu dan mencurahkan pikirannya demi terbitnya artikel literature review ini. Saran dan kritik selalu kami harapkan demi tercapainya manfaat dari penerbitan artikel ini.

\section{DAFTAR PUSTAKA}

[1] Wiknjosastro, H. 2011. Ilmu Kebidanan. Jakarta: Yayasan Bina Pustaka Sarwono Prawirohardjo

[2] World Health Organization. Global health risks: mortality and burden of disease attributable to selected major risks: World Health Organization; 2009.

[3] RISKESDAS] Riset Kesehatan Dasar. (2016). Jakarta: Badan Penelitian dan Pengembangan Kesehatan Kementrian Kesehatan RI

[4] WHO, 2017, WHO Recommendations on Antenatal Care for Positive Pregnancy Eksperience, Jurnal WHO,http://apps.who.int/iris/bits tream/10665/250796/1/97892415 49912eng.pdf?ua=1. Diakses pada 02 Juni 2021.

[5] Kementerian Kesehatan RI. Survei Demografi dan Kesehatan Indonesia (SDKI) 2017. Jakarta: Badan Penelitian dan Pengembangan Kesehatan Kementerian RI. 2017.
[6] Guyton AC, Hall JE. Texbook of medical physiology. Elsevier; 2006.

[7] Astutik yuli R dkk, (2017) Kepatuhan Antenatal Care Ibu Hamil Resiko Tinggi Dengan Ketepatan Rujukandi Desa Sepawon Kecamatan Plosoklaten. JURNAL ILKES (Jurnal Ilmu Kesehatan) Vol. 8 No. 2 Desember 2017.

[8] Erwin Kurniasih. (2020). Hubungan Tingkat Pengetahuan Ibu Hamil Trimester III Tentang Tanda Bahaya Kehamilan Dengan Kepatuhan Antenatal Care (ANC) di Puskesmas Geneng Kabupaten Ngawi. Journal of Chemical Information and Modeling.

[9] Armaya, R. (2018). Obedience of Pregnant Women's in Conducting Antenatal Care Visits and The Influencing Factors. Journal of Public Health Sciences.

[10] Noviati, S. (2018). Kunjungan Antenatal Care Dintinjau Dari Pengetahuan Ibu Hamil Tentang Tanda Bahaya Kehamilan Di Puskesmas Batu Aji Kota Batam Tahun 2019. Jurnal Sehat Masada, XV(1), 33- 38.

[11] Wawan, A dan Dewi M. 2011. Teori \& Pengukuran, Pengetahuan, Sikap Dam Perilaku Manusia. Yogyakarta. Nuha Medika.

[12] Purnami, C. 2006. Hubungan Persepsi Ibu Tentang Sarana Pelayanan KIA Dengan Kunjungan Pemeriksaan Kehamilan (K4) (Studi di Wilayah Kerja Puskesmas Tegal Barat II Kota Tegal Tahun 2006). Jurnal Promosi Kesehatan Indonesia Vol. 2 / No.2 / Agustus 2007.

[13] Jasmawati. 2015. Analisis Hubungan Pengetahuan Ibu Hamil Tentang Antenatal Care Dengan Perilaku Kunjungan Pemeriksaan Kehamilan di Puskesmas. Jurnal Husada Mahakam. Volume III No. 9 hal. 452-521.

[14] Oktavia, L. (2018). Kunjungan Antenatal Care Ditinjau dari Tingkat Pengetahuan Ibu Hamil Tentang Tanda Bahaya Kehamilan. Jurnal.

[15] Pongsibidan, Gabriellyn Sura. (2012). Faktor yang Berhubungan Dengan Keteraturan Kunjungan Antenatal di Wilayah Kerja Puskesmas Kapala Pitu Kabupaten Toraja Utara. [Artikel penelitian] Makassar: Universitas Hasanuddin. 